\title{
SELEÇÃO DE CANDIDATOS AOS CURSOS DE ESPECIALIZAÇÃO *
}

\author{
Maria Sumie Koizumi** \\ Edna Ikumi Umebayashi Takahashi*** \\ Regina Marcia Cardoso de Sousa****
}

KOIZUMI, M.S.; TAKAHASHI, E.I.U.; SOUSA, R.M.C. Seleção de candidatos aos cursos de Especialização. Rev. Esc. Enf. USP, São Paulo, 19(2):111-119, 1985.

As autoras analisam os aspectos a serem considerados no processo de seleçũo de candidatos aos Cursos de Especialização. Apresentam o método empregado no Curso de Especialização em Enfermagem de Cuidados Intensivos da Escola de Enfermagem da USP.

\section{CONSIDERAÇOES GERAIS}

Os Cursos de Especialização e de Aperfeiçoamento têm por objetivo fundamental atender a uma necessidade específica do mercado de trabalho, aprofundando e completando conhecimentos, habilidades e atitudes necessárias ao dominio de funções bem definidas no seu perfil técnicocientífico.

A Resolução n ${ }^{\circ}$ 14/77 do Conselho Federal de Educação (CFE) ${ }^{1}$ define no seu artigo $2^{\circ}$, que os Cursos de Especialização e Aperfeiçoamento destinam-se a graduados e serão ministrados por instituiçōes de ensino superior que ofereçam Curso de Graduação reconhecido ou Curso de Pós-Graduação credenciado, cujas estruturas curriculares abranjam a área de estudos específicos, ou com ela estejam diretamente relacionados.

A Resolução $n^{\circ}$ 1709/79 da Universidade de São Paulo - (USP) ${ }^{3}$, no seu artigo 1, define o Curso de Especialização como aquele ministrado a graduados, sobre objeto delimitado de conhecimento, objetivando a formação de técnicos de alto nível.

- Trabalho apresentado no XXXVI Congresso Brasileiro de Enfermagem - Belo Horizonte, 1984. Publicaçăo autorizada.

** Enfermeira. Professor Assistente Doutor do Departamento de Enfermagem Médico-Cirúrgica। da Escola de Enfermagem da USP - disciplina Enfermagem Médico-Cirúrgica.

** Enfermeira. Mestre em Enfermagem. Professor Assistente do Departamento de Enfermagem Médico-Cirúrgica da Escola de Enfermagem da USP - disctplina Entermagem Médico-Cirúrgica.

*** Enfermeira. Auxiliar de Ensino do Departamento de Enfermagem Medico-Cirúrgica da Esscola de Enfermagem da USP - disciplina Enfermagem MédicoCirágica. 
Ao se criarem Cursos de Especialização, dois aspectos fundamentais devem ser considerados: a demanda do mercado de trabalho e as possibilidades da Instituição que deseja oferecer esses cursos.

Além disso, a Classificação Brasileira de Ocupações ${ }^{2}$ prevê para o profissional enfermeiro as categorias: generalista, sanitarista, obstétrico, puericultor e pediátrico, psiquiátrico, do trabalho, de centro cirúrgico e de terapia intensiva. Isto vem reforçar a necessidade de se criarem Cursos de Especialização, como um dos mecanismos por meio do qual o egresso de um curso de graduação, de cunho generalista, pode melhor se adaptar às necessidades multiformes de um mercado de trabalho em contínuo desenvolvimento.

Considerando-se que um Curso de Especialização é criado na medida em que a demanda é grande e fortemente sentida, tanto pela provável clientela como pela Escola, o processo de seleção dos candidatos se impõe como uma etapa obrigatória.

Neste trabalho são apresentados os itens a serem considerados no processo de seleção de candidatos aos Cursos de Especialização, e como esta vem sendo conduzida no Curso de Especialização em Enfermagem de Cuidados Intensivos da EEUSP.

\section{FINALIDADE DO PROCESSO DE SELEÇÃO DOS CANDIDATOS}

Julga-se que o processo de seleção dos candidatos seja uma das etapas obrigatórias, quando se pretende oferecer um determinado curso. Quando a demanda é pequena ou restrita a determinados núcleos, acredita-se que outros recursos de reciclagem especificos sejam mais adequados para a adaptação desses profissionais.

O processo de seleção tem como finalidade primordial formar grupos que, nas suas características, apresentem manifestações prévias de comportamento, determinadas como básicas para ingresso ao curso.

As necessidades específicas do mercado de trabalho são mutáveis no tempo e no espaço. Ao se propor um Curso de Especialização é necessário, em primeiro lugar, avaliar-se a necessidade real do mercado de trabalho, assim como a demanda existente, ambas analisadas quanto às suas características e distribuição. O diagnóstico resultante desta avaliação, por sua vez, constituirá a base para se programar um conjunto coerente de atividades, capazes de promoverem a completa adaptação de um graduado às suas funções específicas.

$\mathrm{Na}$ análise do mercado de trabalho, é necessário delimitar a área geográfica que se pretende abranger e estimar a provável clientela. Estes dados formarão os subsídios para elaboração dos parâmetros de seleção dos candidatos.

Estudada a provável clientela e delineados os objetivos do Curso, procurando-se sempre coerência entre a Escola e o mercado de trabalho, podem-se construir os critérios para sua seleção. 
Selecionar candidatos aos Cursos de Especialização, seja qual for a área, não é tarefa fácil. Ao se estabelecerem as características do comportamento prévio do candidato, necessário para seu ingresso no curso, é necessário levar-se em consideração, que são profissionais provenientes de diferentes escolas, assim como com experiências diversificadas tanto em tempo como em tipo.

Por outro lado, considerando-se que a diversificação na formação acadêmica e na experiência profissional é desejável para estimular maior troca de experiências entre os alunos, o processo de seleção deve prever a possibilidade desta mesclagem.

Neste particular, considera-se que a formação de critérios objetivos para a seleção passa a ser um método desejável; com isto, poder-se-a minimizar os efeitos da agregação ou de dispersão por determinadas escolas ou instituições.

A determinação do mínimo de vagas para cada grupo de alunos e a periodicidade de cada curso são feitas em função da demanda e das experiências que se pretende sejam oferecidas durante o mesmo. Sendo cursos de cunho predominantemente prático, pois, por definição, visam adaptação profissional ao mercado de trabalho, julga-se que as oportunidades de aprendizado de campo devam ser previstas antecipadamente; consequentemente, o número de vagas estará também limitado pela possibilidade de utilização de campos de trabalho, que servirão como laboratório de aprendizagem.

Nesta etapa, além dos critérios de seleção, os objetivos do curso deverão estar formulados, assim como, o conjunto de atividades a serem desenvolvidos no curso em pauta; isto é importante na medida em que, ao serem operacionalizados os critérios de seleção, a visão global do curso mostre que há coerência em cada uma das suas fases.

\section{SELEÇAOO DE CANDIDATOS PROPRIAMENTE DITA}

Com base nesses dados, foram construidos os critérios de seleção para o Curso de Especialização em Enfermagem de Cuidados Intensivos da EEUSP. Eles foram utilizados para seleção do segundo e terceiro grupo de alunos.

O mercado de trabalho estudado foi o do Município de São Paulo e a população-alvo se estendeu para o Estado de São Paulo. Para os próximos cursos pretende-se analisar o mercado de trabalho numa área mais abrangente e ampliar a população-alvo para outros estados.

Especificamente para este Curso de Especialização, há restrição dos campos de estágio no que se refere ao número de estagiários. Este foi um fator importante na limitação de vagas. Outro fator limitante foi o número de docentes disponíveis para o curso. Atualmente o curso é anual e oferecido no primeiro semestre, com um total de 15 vagas.

A seleção dos candidatos está dividida em duas etapas: delimitação da clientela antes da inscrição ao curso e classificação através de escores determinados por medidas de conhecimento e de experiências anteriores. 


\section{Delimitação da Clientela antes da Inscrição}

Pela análise do mercado de trabalho constatou-se um número significante de enfermeiros que atuam em Unidades de Terapia Intensiva (UTI), e o interesse dos mesmos, por melhor aprimoramento nessa área de atuação. Ao mesmo tempo verificou-se que recém-formados sentiam a necessidade de preparo formal para o seu desenvolvimento nessa área especifica.

Em função desta análise, sentiu-se a necessidade de de início delimitar-se a população-alvo, para aqueles que tivessem tido experiência profissional prévia em UTI. Desta forma, estabeleceu-se, como básico para delimitação da clientela, a experiência mínima de seis meses em UTI.

Inicialmente foi feita uma ampla divulgação do curso, procurando-se atingir toda população-alvo, seja individualmente, seja em grupo. Foram utilizados, como meio de divulgação, o Boletim Informativo Paulista (BIP) da Associação Brasileira de Enfermagem, Seção de São Paulo, e um Informe preparado especificamente para essa finalidade.

Como o Informativo Paulista é distribuído para todos os enfermeiros associados da ABEn, do Estado de São Paulo, por esta via tem sido possivel levar-se a informação a todos os profissionais desta área geográfica. A nota sobre o curso é divulgada uma única vez, um ou dois meses antes do periodo de inscrição ao curso. O conteúdo da divulgação é suscinto e consta basicamente de dados sobre o periodo de inscrição, requisitos, tipo de seleção e período do curso.

O Informe específico, por sua vez, é detalhado e contém todas as informações sobre o curso (Anexo I). Na forma individual é enviado para os enfermeiros que durante o ano tenham solicitado informaçōes e deixado o seu nome e endereço na Secretaria da Escola. E oportuno mencionar que freqüentemente há enfermeiros de outros estados que procuram esta modalidade de curso e a todos eles tem sido enviado o informe de divulgação. Na forma coletiva, ele é enviado para todas as escolas do Estado de São Paulo e para a direção dos Serviços de Enfermagem da maioria dos hospitais do Município de São Paulo que contam com UTT.

Com esta divulgação tem sido obtida uma triagem inicial dos candidatos ao curso. Cumpre lembrar que há estudantes do curso de graduação, não somente desta Escola, que manifestam o interesse em fazer o curso logo após o término do tronco profissional comum. Considerando-se que muitos estudantes, por livre iniciativa, fazem estágios paralelos aos cursos, foi prevista uma abertura para aqueles que têm tido esse tipo de experiência em UTI.

\section{Classificação por Escores}

A seleção propriamente dita é feita por meio de uma prova de conhecimentos e pela análise da experiência profissional.

Na prova escrita é avaliado o conhecimento de enfermagem médico-cirúrgica através de uma situação-problema freqüente em UTI. 
A análise da experiência profissional é feita por meio de entrevista individual, sendo que na inscrição o condidato preenche um formulário sobre essa experiência.

A fim de minimizar a influência de fatores subjetivos, têm sido tomada algumas medidas de precaução. Antes da correção da prova de conhecimentos, as docentes se abstêm de fazer o exame dos documentos apresentados pelo candidato, procurando, com isto, não identificá-lo quanto a origem e experiências. Os critérios de classificação estão claramente definidos e pontuados, de acordo com uma escala de valores pré-estabelecidos, em instrumento próprio (Anexo II).

A prova de conhecimentos é eliminatória e o candidato deve obter nota igual ou superior a cinco para depois passar para a entrevista.

O candidato que obtém nota igual ou superior a cinco é pontuado da seguinte forma:

9,1 a $10,0=5$ pontos
8,1 a $9,0=4$ pontos
7,1 a $8,0=3$ pontos
6,1 a $7,0=2$ pontos
5,0 a $6,0=1$ ponto

Isto significa que, na prova, o candidato pode obter no minimo 1 ponto e no máximo, 5 pontos.

A experiência profissional está categorizada como:

- enfermeiro de cabeceira - aquele que tem como função predominante a execução de cuidados diretos ao paciente $=5$ pontos;

- supervisor de UTI (inclui docente) - aquele que tem função predominantemente administrativa e/ou de supervisão da assistência de enfermagem prestada ao paciente $=4$ pontos;

- estágio após formatura - aquele que após o curso de graduação, realizou estágio específico em UTI $=3$ pontos;

- supervisor de outra área além da UTI - aquele que acumula funções administrativas e/ou de supervisão na UTI em outras áreas = 2 pontos;

- chefe de serviço de enfermagem - aquele que responde pelo serviço de enfermagem do hospital $=1$ ponto;

- estágio paralelo em UTI durante o curso de graduação $=1$ ponto.

A experiência profissional pode ser cumulativa, de acordo com o tempo de exercício do candidato. Assim sendo, nesta parte é feita a somatória de todas as experiências do candidato, o que resulta em um mínimo de 1 ponto e um máximo de 16 pontos.

A somatória dos escores obtidos pelo candidato nos itens conhecimento e experiência, são ordenados na forma decrescente. Os quinze 
primeiros candidatos com os maiores escores são os classificados para o curso.

Quando um mesmo escore é obtido por mais de um candidato, o desempate é feito por dois critérios: tempo de formado e local de atuação. A preferência é dada ao maior tempo de formado e à atuação na UTT.

A experiência neste processo de seleção com dois grupos tem mostrado que o método diminui significativamente a influência dos fatores subjetivos. A objetividade tão preconizada em quaisquer critèrios de seleção, pode ser obtida, em grande parte, com esse esquema.

Por outro lado, considerando-se que uma das finalidades da seleção foi a de homogeneizar o grupo, com base no comportamento prévio pré-estabelecido, julga-se que ela está sendo alcançada. Além disso, a mesclagem do grupo por escola e instituição onde trabalha tem sido obtida como resultado natural do processo de seleção.

Finalmente, cabe ressaltar que o método proposto torna a seleção um processo simples e prático.

KOIZUMI, M.S.; TAKAHASHI, E.I.U.; SOUSA, R.M.C. Selection of graduate nurses for admission to graduate programs in specialization areas. Rev. Esc. Enf. USP, São Paulo, 19(2):111-119, 1985.

The authors analyse the selection process that is being used at the "Escola de Enfermagem da Universidade de São Paulo", for selection of graduate nurses the enrollment in the specialization program on Intensive Care Nursing. They refer the objective and the method used at the selection of candidates, as the results obtained.

\section{REFERENCIAS BIBLIOGRAFICAS}

1. BRASIL. Lel, decretos, etc. Resoluçăo no 14/77. Documenta, Brasilla, (205):487-88, dez. 1979.

2. BRasIL. Ministério do Trabalho. Classificacio brasiloira do ocnpacões. Brasilia, SINE Sistema Nacional de Emprego, 1982.

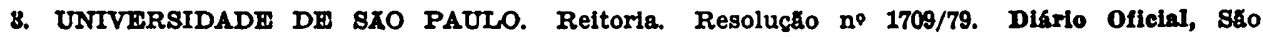
Paulo, 16 out. 1979. 


\section{A NEXO I \\ III CURSO DE ESPECTALIZAÇAOO EM ENFERMAGEM \\ DE CUIDADOS INTENSIVOS \\ $-1984-$}

\section{CLIENTELA.}

O curso destina-se a enfermeiros com experiencia profissional, que sejam apresentados por instituição interessada na assistência de enfermagem ao paciente em estado crítico.

\section{OBJETIVOS}

A partir da visão global obtida durante o curso, o enfermeiro, através de uma metodologia sistematizada, deverá ser capaz de:

1. Identificar, correlacionar e intervir nos problemas de enfermagem apresentados pelos pacientes com desequilíbrio nutricional, hidroeletrolítico e/ou ácido-básico e que apresentam insuficiência respiratória, cárdio-vascular, renal e/ou cerebral;

2. manusear e controlar equipamentos e aparelhos usados nas unidades de assistência ao paciente em estado critico;

3. analisar a problemática da assistência de enfermagem no contexto da Unidade de Terapia Intensiva e o desenvolvimento do trabalho da equipe multiprofissional de saude.

\section{CONTEODO PROGRAMATICO}

1. O papel do enfermeiro em face do paciente com desequilibrio nutricional, hidroeletrolítico e7ou ácido-básico.

2. A assistência de enfermagem ao paciente em estado critico, que apresenta insuficiência respiratória, cárdio-vascular, renal e/ou cerebral. Intervenção de enfermagem na insuficiência respiratória aguda, coronariana aguda, nos estados de choque, no estupor e no coma. Assistencia de enfermagem a pacientes em diálise peritonial, hemodiálise e em nutrição parenteral.

3. Levantamento e análise da problemática da assistencia de enfermagem ao paciente em estado crítico. Papel do enfermeiro e da equipe multiprofissional, no contexto da UTI.

\section{INFORMAgOES GERAIS}

Periodo previsto: de 08 de março a 30 de junho de 1984 (periodo parcial vinte horas semanais).

Carga horária: total de 360 horas de aula, assim distribuidas:

- aulas formais: 50 horas;

- estágio: 130 horas;

- seminários, reuniбes ,discussðes: 130 horas;

- elaboração de trabalhos: 50 horas.

\section{INSCRIÇAOO}

A inscriçăo deverá ser feita pessoalmente na Secretaria do Cursos Extracurriculares, da Escola de Enfermagem da USP, quando o candidato deverá entregar: 
1. requerimento (fornecido pela Secretaria)

2. cédula de identidade (cópia autenticada)

3. 2 (duas) fotografias $3 \times 4$

4. carta de apresentação da Instituição de origem

5. diploma de enfermeiro (cópia autenticada)

6. comprovante de experiência profissional mínima de 6 (seis) meses em UTI.

Data de inscrição: 30 e 31 de janeiro de 1984, das 9 às 17 horas, na Secretaria dos Cursos Extracurriculares.

\section{SELECAAO}

Serão selecionados os primeiros quinze candidatos classificados.

A seleçăo será realizada através de:

10 - Prova de conhecimentos versanđo sobre Enfermagem Médico-Cirúrgica, na qual o candidato deverá obter, no mínimo, nota 5,0 (cinco inteiros). Será realizada no dia $1^{0}$ de fevereiro de 1984, às nove horas, na sala 2.

$2^{\circ}$ - Entrevista e análise da experiéncia profissional dos candidatos aprovados no exame de conhecimentos.

As entrevistas serão realizadas no periodo de 06 a 24 de fevereiro de 1984, das nove às dezessete horas.

\section{MATRICULA}

Deverá ser efetuada nos dias 29/02 e 01/03/84, das nove às dezessete horas.

A taxa de matrícula será de Cr\$60.000,00.

\section{QUALIFICACOES DE ALUTNOS}

$O$ aluno deverá:

1. assistir a um minimo de $70 \%$ das horas de aula;

2. apresentar em tempo hábll os trabalhos que lhe sejam solicitados;

3. submeter-se as provas de avaliação julgadas necessárias pela Coordenaçăo do Curso.

OBSERVAÇAO: O aluno que năo observar as exigencias acima ou năo revelar bom aproveitamento, a júzo da Direçáo da Escola, terá sua matrícula cancelada.

\section{CRITRRIOS DE AVALTAÇAO DO APRFNDIZADO}

O aluno será avaliado através de:

- trabalhos orais e escritos;

- provas de aproveitamento e

- desempenho nos estágios.

\section{COORDEINADORAS DO CURSO}

Maria Sumie Koizumi

Edna Ikumi Umebayashi Takahashi

Săo Paulo, 08 de dezembro de 1983. 


\section{A NEXO II \\ III CURSO DE ESPECIALTZACCAO EM ENFERMAGEM \\ DE CUIDADOS INTEINSIVOS \\ CRITERIOS DE PONTOS PARA SELLECAO}

Nome do candidato:

1. Prova escrita: (notas de 5,0 a 10,0 )

$$
\begin{aligned}
10,0-9,1 & =5 \\
9,0-8,1 & =4 \\
8,0-7,1 & =3 \\
7,0-6,1 & =2 \\
6,0-5,0 & =1
\end{aligned}
$$

2. Experiencia em UTI:

- enfermeira de cabeceira

- supervisora de UTI (inclui docente)

- estágio após formada

- supervisora de área + UTI

- chefe de servico de enfermagem

- estágio durante a graduaçăo TOTAL DE PONTOS $(1 .+2)=$.

\section{Tempo de formada:}

recém-formada anos de formada

4. Onde trabalha atualmente:

UTI

Outra área

(3. 4. = critérios de desempate)

6. Observagoes: 